\title{
Insights Gained into Marginalized Students Access Challenges During the COVID-19
}

\section{Academic Response}

\author{
Ann C. Kimble-Hill, Armando Rivera-Figueroa, Benny C. Chan, Wasiu A. Lawal, Sheryl \\ Gonzalez, Michael R. Adams, George L. Heard, J. Lynn Gazley, and Benjamin Fiore-Walker
}

\begin{abstract}
The American Chemical Society (ACS) Committee on Minority Affairs (CMA) endeavors to support all chemistry faculty and staff as they educate all of our students during this pandemic. While the chemistry education community and the ACS have both provided resources as most institutions transitioned to virtual platforms, this pandemic disproportionally affects our students of color, lower socio-economic and rural backgrounds, and students with disabilities. Specifically, these students must overcome hurdles of technology access, environmental disruptions, and cultural pressures in order to be successful. Therefore, CMA has formulated partnerships with both academic and industrial institutions to highlight some best practices to improve future virtual learning experiences of these oftentimes marginalized students. Specifically, the work presented here examines programs and policies at three academic institutions with very different student body demographics and surrounding learning environments (Indiana University Purdue University Indianapolis (IUPUI), The College of New Jersey (TCNJ), and Los Angeles Community College District (LACCD)) with an attempt to identify variables that enhance marginalized student success in chemistry courses. The combination of their results suggests elements such as access to technology, home responsibility,
\end{abstract}

This is the author's version of the work published in final form as:

Kimble-Hill, A. C., Rivera-Figueroa, A., Chan, B. C., Lawal, W. A., Gonzalez, S., Adams, M. R., Heard, G. L., Gazley, J. L., \& Fiore-Walker, B. (2020). Insights Gained into Marginalized Students Access Challenges During the COVID-19 Academic Response. Journal of Chemical Education. https://doi.org/10.1021/acs.jchemed.0c00774 
and impostor syndrome, that other learning programs should consider to increase virtual learning success. Furthermore, other stopgap measures implemented at industrial partners give insight as to how these considerations can be implemented during virtual internship programs to meet their learning objectives associated with entering their institutional pipeline.

KEYWORDS: First-Year Undergraduate/General Second-Year Undergraduate Upper-Division Undergraduate Graduate Education/Research Curriculum Laboratory Instruction ComputerBased Learning

\section{Introduction}

The ACS Guidelines for Chemistry College Programs, both for two year college and bachelor degree granting programs, are designed toward developing student skills in problem-solving, specific chemistry literature knowledge, and laboratory safety skills.(1,2) The guidelines suggest that colleges should create opportunities for students to adequately interact with instructors and each other. Among the conditions necessary for effective learning are those that encourage active learning, student-faculty contact, and cooperation among students.(3) Studies have shown that regular contact with faculty improves student success, especially for marginalized students such as those that self-identify as underrepresented minorities (URMs) and varying levels of ability. Traditionally, chemistry hands on laboratories have been found to greatly enhance the learning experience.(4) Faculty have found that technological advances such as smartphones, better computing power, and broadband internet have made online instruction very attractive by enabling broader reach with minimal physical infrastructure. $(5,6)$ However, this new reliance on technology lends to a new question: Does the reliance on technology access for teaching chemistry create new barriers for marginalized student success? 
This question became more pertinent in light of the COVID-19 health emergency when most college campuses instantaneously transitioned from traditional formats to online instruction. Given that COVID-19 disproportionately affects marginalized groups,(7-9) it is expected that the health emergency would have greater and compounding effects on their collegiate college experience.(10) The consequences are dire as their performance in general and organic chemistry courses directly correlates with successfully pursuing science related careers.(11) Therefore, this work specifically reflects on the role of access on the impact of the COVID-19 pandemic on marginalized students' chemistry learning outcomes.

\section{Shifting to Virtual Learning}

\section{Indiana University Purdue University Indianapolis (IUPUI)}

IUPUI conducted a survey and a check-in telephone campaign to determine the transition needs of their students. Over 30 percent of the student body participated, with the respondents generally reflecting the IUPUI population.(12) Students reported having challenges with technology, keeping up with the pace, understanding the material, distractions at home, and lack of motivation. Specifically, students expressed concerns due to Wi-Fi connection issues, lack of cameras on computers, lack of access to printers, technical difficulties with video-conferencing software, and lack of access to a desktop or laptop computer. Despite Indiana University providing statewide Wi-Fi hotspots,(13) we received comments where students had to sit in a campus parking lot or a friend's house to access the internet for assignments and synchronous course content. This was particularly problematic when students took online exams where software required higher level web browser specifications, used cameras for proctored exams, or had timers that did not account for intermittent or slow internet signals. Students suggested that 
assistance with loaner laptops and providing home hotspots would mitigate this issue for future learning experiences.

Students also struggled with laboratory classes that transitioned to instructor supplied data projects. As a result, students reported an increase in class related expectations while losing the kinesthetic learning from the lab. This may have been complicated by providing childcare and sharing internet bandwidth with several other members of their family. Prior to COVID-19, many students studied in controlled environments (e.g., library, residential hall) but pandemic shutdowns led to student housing insecurity or communal environments without appropriate or designated home office furniture or space. However, students reported having more flexible study time due to the state stay at home order. Students reported a benefit from their instructors giving time management hints and plans to approach this new workload. This may be even more important for tracking shifting assignment deadlines or newly added assignments to the syllabus.

Students also reported challenges in finding collective meeting times for group projects and study groups. Students had a hard time with professor virtual explanations, and suggested the use of more individualized tutoring using document cameras and class-wide discussion boards/group chats with instructors posting questions to reinforce explanations as asynchronous and communal engagement. Even having individualized communication through email, messaging applications, and text messages bridged the gap between students, their peer/teaching assistants, and instructors.

\section{The College of New Jersey (TCNJ)}

The students in General Chemistry 1 at TCNJ were surveyed about their transitions to online teaching. Many of the students stated that focus was a major issue for them, but the transition 
was relatively smooth. When surveyed about the access issues, $11 \%$ of students demonstrated they had unreliable Wi-Fi some of the time or all the time and $35 \%$ of our students had issues with finding a quiet space to work most of the time or all of the time. As a predominantly white public institution,(14) qualitative interviews provide valuable insight into marginalized students that general surveys may not capture. We conducted interviews with 20 STEM students that were from a campus program that is designed for low income students and those from marginalized groups were very similar to transition issues seen at IUPUI.

Students mentioned major issues with disruptions, especially with synchronous meetings, "I think with having family around it makes it harder to go to class. Like you know my dad doesn't mean anything by it but he's still, he pops in my room when I'm in the middle of the lecture." Wi-Fi access was more problematic for our low income students, which made learning difficult, "My Wi-Fi was like lagging so the professor was in the middle of talking about something and then I couldn't hear. I couldn't listen to anything. It just kind of went like "zzzt", and then she was already on like another concept. So I didn't hear it so I had to ask. And that wouldn't happen in person." Students from marginalized groups are more likely to be dealing directly with COVID-19 infections, $(7,8)$ which appeared in our interviews, "My brother tested positive for COVID and we were, like, in a panic mode because a family friend just died from it." A student also suffered from family income loss, “When my mom wasn’t working because her job shut down and I was panicking," which led to the student seeking for additional work, "I need to get a job in a hospital. So I can help my family out somehow. But I didn't want my grades to suffer. So I was like, I'm not sure if I want to get it [a job in a hospital] now." This qualitative data is important to understand how our course design needs to adjust for systemic issues.

\section{Perceived Changes in Chemistry Learning Experiences for Marginalized Students}


To further identify relationships and insight into the immediate needs of marginalized students learning chemistry online, we surveyed students from the Los Angeles Community College District (LACCD). LACCD's nine colleges offer educational opportunities to students in 40 cities and communities serving one of the most diverse areas in the U.S. in terms of ethnicity, age, unit load, educational goal, and language spoken at home.(15) All LACCD students were provided a free laptop upon request and free internet through Los Angeles public utilities throughout the pandemic.

We designed a multiple-choice survey distributed among all chemistry students at LACCD (General Chemistry, Organic Chemistry, Biochemistry, Qualitative Chemistry, and Independent Studies in Chemistry (Research). The survey was built to identify relationships between (1) demographics, (2) online lecture skills, (3) online laboratory experience skills, and (4) common challenges and/or barriers for learning. The targeted skills were suggested to prepare for future science education as well as workforce entry. The anonymous and voluntary survey was open for 1 week, with a 19 percent response rate (>95\% confidence intervals, 5\% margin errors). Survey respondents were asked about their preference for the delivery mode and their challenges in access (e.g., tutors, office hours, adequate space to study, technology, safe space study, counseling, auxiliary aids), time management, managing family responsibilities, and insecurities (e.g., financial, food, housing). Although URMs reported challenges regarding financial, housing, and food insecurity, it should be noted that this group was second to Asians, and URMs reported 50\% less insecurity in specific cases such as food and housing.

For online delivery, both URMs and white students preferred a combination of synchronous and asynchronous delivery for lecture content. For lectures, a higher percentage of URMs students preferred asynchronous over synchronous when compared to White students. This phenomena 
could be related to URM students reporting challenges accessing a safe and adequate space to study. Similarly, both groups report time management as a challenge that is minimized in asynchronous learning. In addition, we found that self-identified Hispanics and Native Hawaiian largely prefer a combination approach, while Blacks or African American and White groups mostly choose asynchronous. We proposed that Hispanics and Native Hawaiians may have language barriers (ESL/bilingual) thereby preferring further verbal explanation of convoluted and difficult terminology and methodology in lab manuals.(16)

In regards to challenges preventing online success, URMs identified their biggest challenges as managing family responsibilities and time, followed by access to an adequate and safe space to study. Time management was the biggest challenge identified by other ethnic groups, while an adequate and safe space to study was $\sim 3 \%$ higher for URMs compared to Whites and Asians groups. White students identified access to office hours as a challenge at a much higher percentage than URMs. However, it is interesting to note that both groups report a similar percentage regarding access to tutors. This could be related to previous reports of URM fear of faculty power dynamics and asking for help, leading to decreased attendance at instructor office hours than their White peers.(17-20) This observation is important as this may be related to URM's lack of effort reaching out to faculty as mentors and advisors, which may increase student retention and can then help URMs not only to complete a career in chemistry, but also to either further their education or enter the workforce. Furthermore, it can also represent a measure of the effort from colleges ensuring that students have access to faculty when learning online.(21) Specifically, the ACS 2YCC Guidelines, suggest that for online courses colleges should ensure adequate access to faculty.(1) 
When considering the guideline's targeted skills for chemistry students, URMs reported larger challenges than their White peers in communication, literature/information management, and problem solving. The former two aspects are linked to the previously mentioned reflections; however, problem solving requires a deeper analysis. Greater than $10 \%$ of URMs reported difficulty with several problem-solving skills including understanding abstract concepts as well as laboratory outcomes such as designing/executing an experiment, using fundamental uncertainties, and using appropriate laboratory skills. The laboratory items are no surprise, as they highlight the skills translated by in person explanations and kinesthetic learning in a laboratory setting.

\section{Curricula That Were Designed for Marginalized Groups Were Disrupted}

At Xavier University of Louisiana, the success of science programs in preparing students, particularly African-American students, for health professions has been widely reported.(22) These programs have been developed and refined over several years and tailored to serve Xavier's specific student population. Lower-level science courses, particularly general chemistry and organic chemistry, are coordinated and standardized across all sections.(23) Strategies incorporated in the curricula are aimed at developing a strong network of peer support and cooperative learning. There was considerable concern about the loss of this critical aspect of the programs upon transition to remote learning. Weekly general chemistry drill sessions, consisting of quizzes and group problem solving, that are normally facilitated by upper class student instructors, could not be transferred to remote learning on short notice. The loss of peer-led instruction and teamwork negatively impacted opportunities for students to develop their learning communities. While access to peer tutoring was provided online by appointment, 
students no longer had the benefit of weekly drop-in group review sessions. For many students, their personal situations were similar to those described above which hindered their learning.

\section{Universal Design for Visually Impaired Students Could Support Students with Language Barriers}

The rapid shift to remote teaching has the capacity to further marginalize students with disabilities, particularly in terms of instructors not having sufficient time to consider accessibility of courses. For example, students with vision loss, would use models more extensively in understanding the spatial aspects of chemistry, and would need direct interaction with a professor.(24-26) For students with hearing loss, although some video conferencing platforms have the capability of generating live closed captioning, this captioning has issues with jargon and chemistry-specific terms, and the lack of resolution in video conferencing can hamper lipreading and CART transcription services.(27)

A student with disabilities faces an immediate barrier when layers of accommodation are removed or more difficult to obtain in a timely fashion. A student who relies on the assistance of other students or trained experts in the class, such as a student who is granted a note-taker, would be directly impacted by the online shift. While it may still be possible for that student to get their notes taken, the extra steps in transferring notes slows down the learning process.

\section{Adapting Industrial Internship Experiences to Virtual Platforms}

During the COVID-19 pandemic, most companies adapted to a virtual workforce and modified recruiting strategies, including internships. Internships are an essential tool for employers to maintain a robust talent pipeline that benefits both the employer and the student. Some companies completely canceled their internship programs while others decided to honor their 
commitment to students and continued their programs in a virtual fashion enabling pipeline continuity and cementing their brand with the talent by providing a positive experience that showcases the employer's commitment during times of economic uncertainty.(28) In the life sciences and technology industry, lack of continuity of internship programs can adversely affect progress in workforce diversification. With only $\sim 22 \%$ of bachelor's degrees in STEM conferred to URMs, access to internship programs for minorities becomes a critical recruiting tool.(29) For students, the loss of income, skill development, and professional networking opportunities gained during a summer internship could irreparably disrupt and even permanently derail educational journeys for thousands of marginalized students.(30)

Considering the challenges that marginalized groups face during the pandemic, the employer must ensure that the program is designed to provide an experience that shows the work culture for a given company and to learn valuable skills. Furthermore, the scope of project and critical skills must still include those generally developed during a hands-on laboratory setting or manufacturing floor experience. Therefore, an employer will have to intentionally design virtual projects that cause students to develop skills in problem solving, analytical thinking, research, teamwork, data analysis, and proposing practical solutions.

\section{Robust Training Program for Interns and Supervisors}

Prior to initiating the program, organizations should consider providing training that prepares supervisors to empower students to use their voices and be present. Covering topics such as unconscious bias and psychological safety may foster a safe work environment such that interns do not experience fear of being insulted or marginalized due to stereotypes or biases, and are encouraged to share their diverse ideas and insights, as well as feel respected and valued. 
Educating students on these topics enables the students to communicate challenges without fear of retaliation and feel welcomed and integrated from the beginning.

\section{Equipment and Accessibility Tools}

Employers should provide appropriate equipment to set up a work from home environment including computer and ergonomic and accessibility tools, and appropriate training on use and prevention of ergonomic injuries. Having a discussion on specific needs for the intern will create a more equitable environment. Appropriate examples include determining the student's need for the institution to provide a hot spot or ergonomic/accessibility accessories.

\section{Establish Effective Processes and Ongoing Support}

Initial integration with the team must onboard students from day one. This should include an online structure of support, mentorship, and ongoing education; an established process for tracking progress, feedback loops, networking opportunities with work groups, and other company resources including employee resource groups, affinity groups, and social media channels. The length of the program and appropriate workload should be related to a student's major, be challenging, be recognized by the organization as valuable, and must fill the entire work term. Paying interns ensures that successful students who cannot afford to work for no pay or to pay for college credits are not overlooked, particularly for marginalized groups that must contribute to their household income.

Housing and relocation assistance helps to eliminate many of the challenges that marginalized groups face at home. This will ensure that students will have a safe and appropriate work-fromhome environment, as well as allow them to experience living in the city where the employer is located. 


\section{Addressing the Access Problem for Marginalized Chemistry Students}

Looking forward, faculty are now preparing for a new class of online learners including first years, many of whom have reported that their final year of high school was simply suspended rather than continued remotely. Faced with the new reality of social distancing, faculty are receiving training, and instructional teams are working together to develop plans for delivering courses to students in such a way that the features that have been the backbone of the programs can be maintained.

Students from marginalized groups have general emerging themes that arose as hindrances in a virtual learning environment: access to safe and adequate study spaces, time management and home responsibilities, and building a STEM community that included access to and meaningful relationship-building with peers and faculty. The few access barriers that we have identified in this preliminary analysis may directly affect retention, and hence, successful completion and workforce participation. Therefore, it is key to mitigate the effect of this COVID-19 transition on marginalized students' learning experiences, perceptions, and choices. Furthermore, as students from marginalized groups may experience intersectional identity, imposter phenomenon, and perceived negative relationship(s) with faculty and staff, it is important to consider the role of relationship building toward future mentorship to help students successfully navigate their education pathway and/or their career exploration. This work also suggests a need to revisit specific content delivery approaches shown to improve marginalized student success as instructors are designing future online curriculum.

The authors declare no competing financial interest.

\section{Acknowledgments}


We are thankful for survey data collection and analysis discussed in this work contributed by Jessicah Rauch, Clif Marsiglio, and Michele Hansen (IUPUI Institutional Research and Decision Support); TCNJ Department of Chemistry and Lynn Gazley’s research students; Anna Badalyan (Institutional Effectiveness), Roberto Carballido, and Katie Price (LACCD). Data collection and analysis were conducted with the approval of each institution's Institutional Review Board (IRB). 


\section{References}

(1) ACS Guidelines for Chemistry in Two-Year College Programs; American Chemical Society: Washington, DC, 2009.

(2) ACS Guidelines and Evaluation Procedures for Bachelor's Degree Programs; American Chemical Society: Washington, DC, 2015.

(3) Hurtado, S.; Eagan, M. K.; Tran, M. C.; Newman, C. B.; Chang, M. J.; Velasco, P. We Do Science Here": Underrepresented Students' Interactions with Faculty in Different College Contexts. Journal of Social Issues 2011, 67 (3), 553-579.

(4) Ruddick, K. W. Improving chemical education from high school to college using a more hands-on approach. Ph.D. Thesis, The University of Memphis, 2012.

(5) Zhang, D.; Nunamaker, J. F. Powering E-Learning In the New Millennium: An Overview of E-Learning and Enabling Technology. Information Systems Frontiers 2003, 5 (2), $207-218$.

(6) Dede, C. Planning for neomillennial learning styles: Implications for investments in technology and faculty. Educating the net generation 2005, 5,1-32.

(7) Garg, S.; Kim, L.; Whitaker, M. Hospitalization rates and characteristics of patients hospitalized with laboratory-confirmed coronavirus disease 2019 $\square$ COVID-NET, 14 States, March 1-30, 2020. Morbidity and mortality weekly report MMWR. 2020, 69 (15), 458 .

(8) Racial \& Ethnic Minority Groups. https://www.cdc.gov/coronavirus/2019-ncov/needextra-precautions/racial-ethnic-minorities.html (accessed 2020-06-15). 
(9) Gross, C. P.; Essien, U. R.; Pasha, S.; Gross, J. R.; Wang, S.-y.; Nunez-Smith, M., Racial and Ethnic Disparities in Population Level Covid-19 Mortality. medRxiv, May 11, 2020, DOI: $10.1101 / 2020.05 .07 .20094250$ Sife, A.; Lwoga, E.; Sanga, C. New technologies for teaching and learning: Challenges for higher learning institutions in developing countries. Int. J. Educ. Dev. Using ICT 2007, 3 (2), 57-67.

(11) Harris, R. B.; Mack, M. R.; Bryant, J.; Theobald, E. J.; Freeman, S. Reducing achievement gaps in undergraduate general chemistry could lift underrepresented students into a "hyperpersistent zone. Science Advances 2020, 6 (24), eaaz5687 DOI: 10.1126/sciadv.aaz5687 IUPUI. Rankings \& Campus Statistics. https://www.iupui.edu/about/rankingsstatistics.html (accessed 2020-06-15). Jones, C. Indiana University provides free Wi-Fi access in response to COVID19 crisis. https://news.iu.edu/stories/2020/03/iu/releases/24-free-wifi-access-parking-lothot-spots.html (accessed 2020-06-15). TCNJ Student Population Stats. https://www.collegefactual. com/colleges/thecollege-of-new-jersey/student-life/diversity/ (ac-cessed 2020-06-17). All Reports. http://laccd.edu/Departments/EPIE/Research/Pages/All-Reports.aspx (accessed 2020-06-16). Sirhan, G.; Reid, N. An approach in supporting university chemistry teaching. Chem. Educ. Res. Pract. 2002, 3 (1), 65-75. 
that Predict Interactions with Institutional Agents at Community Colleges HSI and NonHSI. Journal of Applied Research in the Community College 2019, 26 (1), 45-60.

Dika, S. L.; Pando, M. A.; Tempest, B. In Investigating the role of interaction, attitudes, and intentions for enrollment and persistence in engineering among underrepresented minority students, ASEE Annual Conference \& Exposition, New Orleans, LA, June 26-29, 2016, No. 17069.

Eagan, K.; Figueroa, T.; Hurtado, S.; Gasiewski, J. In Faculty accessibility cues: Opening the doors to classroom communications; Annual Forum of the Association for Institutional Research, New Orleans, LA, 2012. Zambrana, R. E.; Ray, R.; Espino, M. M.; Castro, C.; Douthirt Cohen, B.;

Eliason, J. Don't Leave Us Behind" The Importance of Mentoring for Underrepresented Minority Faculty. American Educa-tional Research Journal 2015, 52 (1), 40-72. Lisberg, A.; Woods, B., Mentorship, mindset and learning strategies: an integrative approach to increasing underrepresented minority student retention in a STEM undergraduate program. J. STEM Educ. 2018, 19 (3).

$$
\text { Hannah-Jones, N. A Prescription for More Black Doctors: How does tiny Xavier }
$$

University in New Orleans manage to send more African-American students to medical school than any other college in the country? https://www.nytimes.com/2015/09/13/magazine/a-prescription-for-more-blackdoctors.html (accessed 2020-06-16). Adams, M. R., Setting the Stage for Success: General Chemistry at Xavier University. In Strategies for Success; Benjamin Cummings Publish, 2002; Vol. 38. 
chemistry students who are blind or visually impaired. J. Chem. Educ. 2005, 82 (10), 1513.

Supalo, C. A.; Humphrey, J. R.; Mallouk, T. E.; Wohlers, H. D.; Carlsen, W. S. Examining the use of adaptive technologies to increase the hands-on participation of students with blindness or low vision in secondary-school chemistry and physics. Chem. Educ. Res. Pract. 2016, 17 (4), 1174-1189. Miner, D. L.; Nieman, R.; Swanson, A. B.; Woods, M. Teaching chemistry to students with disabilities: A manual for high schools, colleges, and graduate programs; ERIC: 2001. Pagano, T.; Ross, A. D. Teaching Chemistry to Students with Disabilities: A Manual For High Schools, Colleges, and Graduate Programs. 4.1 ed.; American Chemical Society's Committee on Chemists with Disabilities, 2015.

$$
\text { Stansell, A. U.S. Internship Hiring Cut in Half Since COVID-19 Crisis. }
$$

https://www.glassdoor.com/research/internship-hiring-coronavirus/ (accessed 2020-06-15). James, S. M.; Singer, S. R. From the NSF: The National Science Foundation's Investments in Broadening Participation in Science, Technology, Engineering, and Mathematics Education through Research and Capacity Building. CBE $\square$ Life Sciences Education 2016, 15 (3), No. fe7. Ladner, R.; EchoHawk, S.; Wilkerson, B. D.; Burge, Q. B. a. J.; Melton, M. F.; Ellison, M.; Gates, A. Q.; Farmer, R.; DeLyser, L. A.; Saujani, R.; Gittins, R.; Pittsford, L.; Hogan, T.; Reid, K. W.; Rizvi, N.; Russell, C.; Franklin-Davis, D.; Tamez, R.; 
Horting, K.; Guendelman, A. An Open Letter to Employers on Summer 2020 Internship Commitments Amidst the COVID-19 Crisis. https://anitab.org/blog/open-letter-summer2020-internship-covid-19/ (accessed 2020-08-06). 